\title{
THE ATRIAL PRESSURE TRACING IN CONGENITAL HEART DISEASE
}

\author{
BY \\ R. J. SHEPHARD \\ From the Cardiac Department, Guy's Hospital \\ Received November 3, 1954
}

A case of pulmonary stenosis showing terminally the signs of an associated tricuspid incompetence prompted an enquiry into the frequency of tricuspid incompetence in congenital heart disease. From the theoretical standpoint, two distinct types of incompetence-structural and functional-may be recognized. It is well known that structural incompetence may be associated with organic abnormalities of the valve region, particularly in Ebstein's disease. However, functional incompetence is generally held to be rare in congenital heart cases, although instances of pulmonary stenosis showing this complication have been described (Biörck et al., 1952; and Campbell, 1954). Against this view must be set the fact that the clinical detection of tricuspid regurgitation is difficult unless the condition is advanced, and lesser degrees of regurgitation may thus have escaped notice.

The development of electro-manometric technique has allowed a detailed examination of human atrial pressure curves, and some knowledge of their form in the presence of tricuspid regurgitation has been obtained by a study of cases with rheumatic heart disease (Bloomfield et al., 1946; Müller and Shillingford, 1954; and Korner and Shillingford, 1954). It was therefore thought of interest to review tracings from a large group of pulmonary stenosis cases with particular reference to possible evidence of tricuspid regurgitation. Tracings from three cases of Ebstein's disease have also been examined, and the diagnostic value of an abnormal atrial pressure curve is discussed.

\section{Normal Atrial Pressure Curves}

The pattern of the normal atrial pressure curve varies considerably according to the degree of damping that is introduced into the system, but with optimal damping and natural frequency the curve assumes the form illustrated in Fig. 1. This curve was first described for the experimental animal (Wiggers, 1923), but Fowler et al. (1953) have now confirmed that the human tracing has a similar form, and from a large group of observations on normal subjects quote the following average pressures for the various waves. The pressures are given in $\mathrm{mm}$. $\mathrm{Hg}$ from a line $10 \mathrm{~cm}$. anterior to the spine.

$$
\begin{array}{ll}
a \text { wave } 5.5 \mathrm{~mm} . & x \text { descent } 3.0 \mathrm{~mm} . \\
c \text { wave } 3.5 \mathrm{~mm} . & x^{\prime} \text { descent } 1.5 \mathrm{~mm} . \\
v \text { wave } 4.5 \mathrm{~mm} . & y \text { descent } 2.5 \mathrm{~mm} .
\end{array}
$$

The recording system used in this laboratory (Southern Instruments electro-manometer with Kelvin-Hughes direct writing recorder) had a satisfactory natural frequency ( $>15$ c.p.s. with No. 8 Cournand cardiac catheter attached). The degree of damping was normally not sufficient to obliterate any of the atrial waves, although in some patients with a large $a$ wave, the $c$ wave did tend to merge into the descending limb of the $a$ wave. 


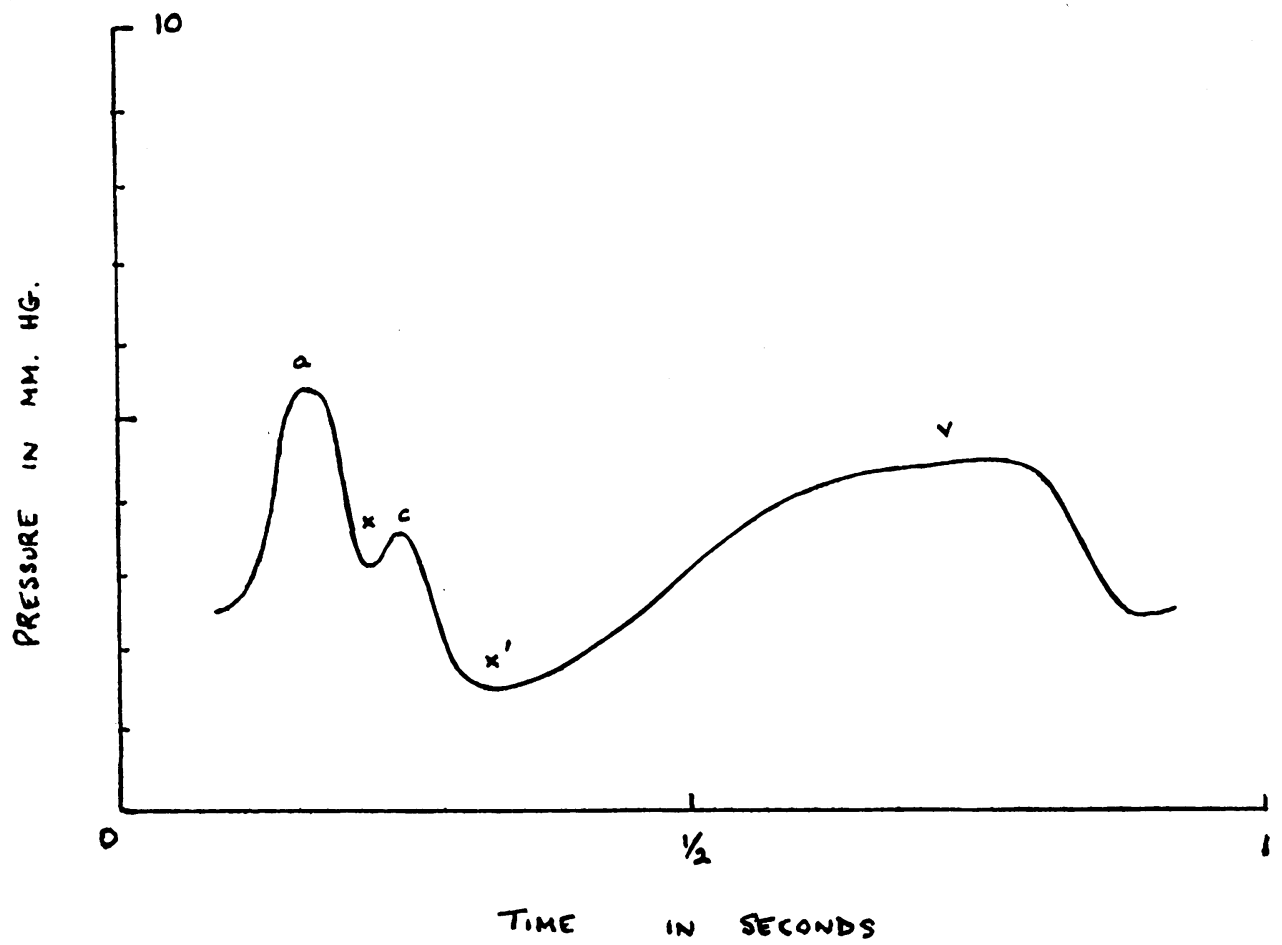

FIG. 1.-Average atrial pressure curve in normal subjects. The average heights of the $a, c$, and $v$ waves and the average depth of the $x, x^{\prime}$, and $y$ descents are given in the text.

\section{Atrial Tracings in Pulmonary Stenosis}

Fifty-one tracings from 40 different cases have been examined. Generally the outstanding feature is a large $a$ wave (Fig. 2). The atrial systolic reading is increased in many forms of congenital heart disease (Shephard, 1954), but this is particularly true of pulmonary stenosis, the average value in the present series being $10 \mathrm{~mm}$. $\mathrm{Hg}$. In 18 cases it was not possible to detect a distinct $c$ wave; it was present in the remaining 22 , although usually represented only by a small hump of $1 \mathrm{~mm}$. or less on the descending slope of the $a$ wave. The $x^{\prime}$ descent was well marked and clear cut in most tracings, the average value $(2.3 \mathrm{~mm}$. $\mathrm{Hg}$ ) being close to normal. Extreme values were 10 and $-2 \mathrm{~mm}$. $\mathrm{Hg}$, but most lay in the range $0-5 \mathrm{~mm}$. $\mathrm{Hg}$. The $v$ wave was again of normal amplitude in most instances, the average for the group being $4.5 \mathrm{~mm}$. $\mathrm{Hg}$. The decline of the $v$ wave was perhaps a little less marked than in the normal person, the average pressure at the $y$ descent being $3.7 \mathrm{~mm}$. Hg.

In 10 of the 40 cases, the rising phase of the $v$ wave showed an additional pressure fluctuation. Often small, this in a few instances overshadowed the true $v$ wave (Fig. 2). This corresponds in timing with the $s$ wave, described as a feature of tricuspid incompetence by Bloomfield et al. (1946), and it seems possible that this additional wave indicates some degree of functional regurgitation at the tricuspid valve. Korner and Shillingford (1954) have described obliteration of the $x^{\prime}$ descent as a further feature of tricuspid leak in rheumatic patients, but it is unlikely that these findings are applicable to pulmonary stenosis. In a normal heart the $x^{\prime}$ descent is probably initiated by two factors-descent of the base of the heart, and active relaxation of the atrium. In rheumatic heart disease, the atrium is diseased and often fibrillating, so that while the first factor may operate, active relaxation is not possible. On the other hand, in pulmonary stenosis the atrium is large 

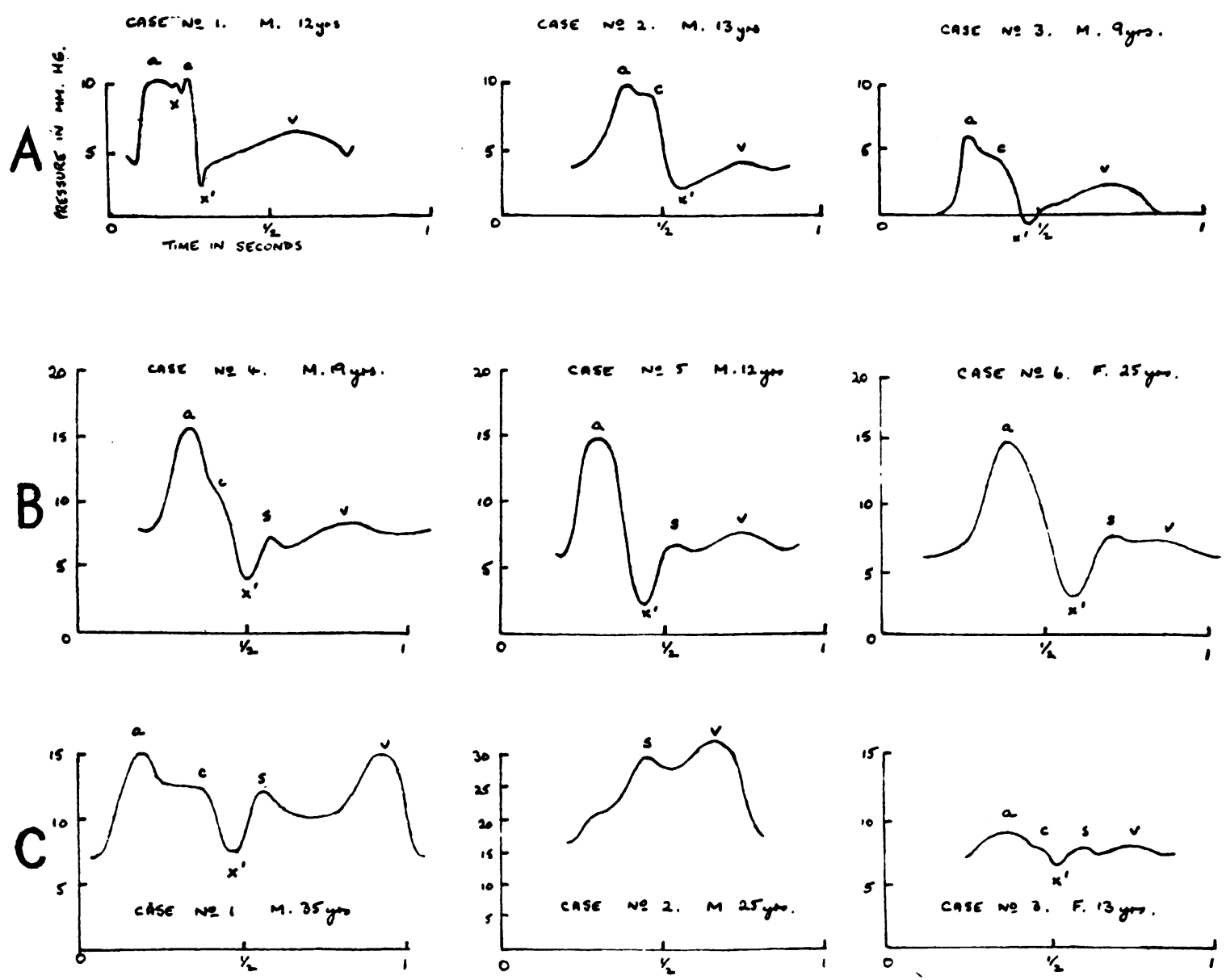

FIG. 2.-Atrial pressure curves where the pressure on the right side of the heart is raised. (A) From 3 typical cases of simple pulmonary stenosis with the $c$ wave almost hidden in the $a$ wave. (B) From 3 severe cases of pulmonary stenosis where the average right ventricular systolic pressure was $153 \mathrm{~mm}$. $\mathrm{Hg}$, showing an $s$ wave: this was thought to indicate some degree of tricuspid regurgitation. (C) From 3 cases of Ebsteins disease, showing $s$ waves also (see text).

and muscular, and the $x^{\prime}$ descent is potentially greater than normal; obliteration of the $x$ descent would not therefore be expected except as a late sign of tricuspid leak.

It might be anticipated that tricuspid regurgitation would develop particularly in those cases where the right ventricular pressure was high, or the valve region had been subjected to strain for a long period. It therefore seems significant that the 10 cases showing an $s$ wave were all particularly severe, the average right ventricular systolic pressure being $153 \mathrm{~mm}$. $\mathrm{Hg}$, as compared with $112 \mathrm{~mm} . \mathrm{Hg}$ for the remainder of the group. Further, most of these 10 were adults, the average age for the group being 21 years, and a number showed severe electrocardiographic evidence of myocardial strain. However, clinical evidence of tricuspid regurgitation was not noted in any of these patients. The one case showing clinical signs of this complication was even older (37 years); he died of ventricular fibrillation a few days after an operation that had been successful in relieving his stenosis.

\section{Atrial Tracings in Ebstein's Disease}

The electro-manometer records of three cases are available for analysis. These provide by way of comparison the pressure tracings associated with a congenital structural abnormality of the 
tricuspid valve region. The pattern and average level of pressure in the atrium varies considerably, probably owing to differences in the amount of muscle incorporated into the effective atrial chamber, but the mean atrial pressure is high in all three patients. Disturbances of electrical conduction are shown by a delayed $c$ wave in Cases 1 and 3, and auricular fibrillation in Case 2. The main feature that is common to the three tracings seems an $s$ wave. This is similar to the $s$ wave seen in a number of the pulmonary stenosis cases, but is more marked, as might be expected from the higher mean atrial pressure and the more obvious clinical manifestations of tricuspid incompetence.

\section{Discussion}

Clinical cases of tricuspid incompetence are rare in congenital heart disease, being confined to organic abnormalities of the tricuspid region and long standing cases of simple pulmonary stenosis. However, study of a large group of pressure tracings from the right atrium suggests that a smaller. degree of tricuspid leak may be more common, particularly in older cases of pulmonary stenosis. The basic features of the regurgitant tracing seem to differ slightly from those observed in mitral stenosis, probably owing to the more healthy condition of the right atrium, and a large $x^{\prime}$ descent may precede the $s$ wave. Many cases of pulmonary stenosis withstand a high right ventricular pressure without developing any evidence of regurgitation, and this can again be attributed to the healthy condition of the myocardium and atrio-ventricular ring during youth. At cardiac catheterization it is common to find a greatly enlarged right atrium, while the tricuspid orifice is still apparently of normal size. However, it is not surprising to find that as adult life is reached, the more severe cases develop some dilatation in the region of the tricuspid valve leading to functional incompetence. It is well recognized that functional incompetence is a reversible condition provided that severe liver damage has not occurred; however, in the absence of treatment, it is liable to progress towards a fatal conclusion. The fact that some cases of pulmonary stenosis may show electromanometric signs of tricuspid incompetence before reaching the age of 21 is a further pointer to the importance of early treatment in this condition.

The main diagnostic features of catheterization in Ebstein's disease have previously been considered the coiling of the catheter in the massive right atrium, and a left-to-right shunt through an atrial septal defect (Baker et al., 1950). Catheterization is not to be undertaken lightly in Ebstein's disease owing to certain special risks (Engle et al., 1950), but if it does prove necessary the present study suggests that certain features of the pressure tracing, particularly a high mean atrial pressure and a regurgitant $s$ wave may help in reaching the diagnosis.

\section{SUMmaRY}

Atrial pressure tracings have been examined in 40 cases of pulmonary stenosis. The main feature in all was a large $a$ wave, but ten older cases with a high right ventricular pressure showed also an abnormal $s$ wave, suggesting the development of some functional tricuspid incompetence. In three cases of Ebstein's disease, the mean atrial pressure was high, and an $s$ wave confirmed the presence of tricuspid incompetence.

\section{REFERENCES}

Baker, C., Brinton, W. D., and Channell, G. D. (1950). Guy's Hosp. Rep., 99, 247.

Biörck, G., Axén, O., and Thorson, Å. (1952). Amer. Heart J., 44, 143.

Bloomfield, R. A., Lauson, H. D., Cournand, A., Breed, E. S., and Richards, D. W. (1946). J. Clin. Invest, $25,639$. Campbell, M. (1954). Brit. Heart J., 16, 273.

Engle, M. E., Payne, T. B., Bruins, C., and Taussig, H. S. (1950). Circulation, 1, 1246.

Fowler, N. O., Westcott, N., and Scott, R. C. (1953). Amer. Heart J., 46, 264.

Korner, P., and Shillingford, J. (1954). Brit. Heart J., 16, 447.

Müller, O., and Shillingford, J. (1954). Brit. Heart J., 16, 195.

Shephard, R. J. (1954). Ph. D. Thesis, University of London.

Wiggers, C. J. (1923). Circulation in Health and Disease. 2nd Ed., Lea \& Febiger, Philadelphia. 